\title{
VERMEER Y CANALETTO: DOS PRECURSORES DE LA FOTOGRAFÍA. UNA APROXIMACIÓN A LA VISIÓN FOTOGRÁFICA
}

\section{VERMEER AND CANALETTO: PRECURSORS OF PHOTOGRAPHY. AN APPROACH TO PHOTOGRAPHICVISION}

José-María Castillo-Pomeda ${ }^{1}$. Universidad Francisco de Vitoria de Madrid, España. ohcastillo@gmail.es

\section{RESUMEN}

Seguramente afirmar que dos pintores, dos maestros sin relación aparente, habrían sido fotógrafos de haber nacido en nuestra época, no es más que una frase propia de un titular sensacionalista. Pero, lo que sí es seguro es que, tanto Jan Vermeer (Delft, 1632) como Giovanni Antonio Canal, más conocido como "el Canaletto" (Venecia, 1697) resolvieron "fotográficamente" los problemas que les presentaba la perspectiva, no hacía mucho tiempo inventada o descubierta por el arquitecto Brunelleschi. Ambos usaron la cámara oscura sin ningún reparo aunque, eso sí, amparándose en el más absoluto de los secretos, no sólo porque su prestigio como artistas se habría visto menoscabado, sino porque en esa época, aún podías acabar en la hoguera si algún inquisidor confundía ciencia con brujería. En este trabajo analizo las técnicas "fotográficas" que ambos utilizaban y como se puede afirmar que ambos tenían una visión de la realidad que puede calificarse así: fotográfica.

PALABRAS CLAVE: visión fotográfica, perspectiva, cámara, pintura, Vermeer, Canaletto.

\section{ABSTRACT}

Probably, asuming that two painters, two masters without an obvious relation would have been photographers if they have been born in our time is nothing but the header of some sensationalist article. Anyway, what we can say for sure is that Vermeer and Canaletto solved in a photographical way the problems that perspective, invented by the architect Brunelleschi, presented. The two of them used the camera obscura without doubt, besides the fact that they never revealed it. They kept it in secret, not only to preserve their artistic prestige but also because at that time you could be burnt at the stake if some inquisitor mistook science for sorcery. Through this work I will analyze the "photograpic" techniques that both of them used in order to aver that they indeed had a photografic vision of reality.

KEY WORDS: photographic vision, perspective, camera, painting, Vermeer, Canaletto.

\footnotetext{
1 José María Castillo-Pomeda: realizador de televisión, fotógrafo, y profesor universitario español. Doctor en Comunicación Audiovisual y autor de varios libros sobre lenguaje audiovisual, fotografía, iluminación y realización televisiva.
} 


\section{Cómo citar el artículo:}

Castillo-Pomeda, J. M. (2016). Vermeer y Canaletto: dos precursores de la fotografía. Una aproximación a la visión fotográfica. Revista de Ciencias de la Comunicación e Información, 21(1), 57-71.

doi: http://doi.org/10.35742/rcci.2016.21(1).57-71

\section{INTRODUCCIÓN}

Cuando el arquitecto Brunelleschi, a principios del Quatrocento, inventa la perspectiva artificialis, para solucionar los problemas de presentación de sus bocetos, seguramente estaba lejos de sospechar la trascendencia que su descubrimiento iba a tener. Se iba a desencadenar una revolución sólo comparable en la Historia del Arte con la aparición del impresionismo o del cubismo, porque no suponía un cambio en la forma de pintar, lo era en la forma de ver. Pero la nueva forma de representar la realidad, tal como la vemos y no de la forma más conveniente en cada caso, como se venía haciendo hasta entonces, planteó multitud de problemas técnicos que los artistas no siempre eran capaces de resolver. Así, los escorzos, los fondos con punto de fuga o los tamaños en función de la distancia, no fueron perfectamente resueltos hasta que apareció, siempre entre sombras y receloso secretismo, la herramienta definitiva: la cámara oscura.

\section{OBJETIVOS}

\section{Objetivo principal:}

- Demostrar la práctica habitual por parte de los pintores post renacentistas, de la realización de bocetos con la ayuda de la cámara oscura. Con ello se conseguía solucionar los problemas que la perspectiva plantea.

\section{Objetivos:}

- Descubrir si la convergencia del uso de la cámara oscura con el descubrimiento de la perspectiva por el arquitecto Brunelleschi, es algo más que una coincidencia y fue originado por la observación de la realidad a través de ella.

- Analizar la obra de dos de los pintores que dominan la perspectiva con una perfección absoluta, buscando evidencias que demuestren que su "visión fotográfica" parte del uso de la cámara, lo cual no sólo no es un demérito, como ellos mismos podían pensar, sino que abre una nueva forma de ver e interpretar la realidad.

\section{METODOLOGÍA}

La base metodológica empleada pasa por enfocar el concepto de "visión fotográfica", que no surge con la fotografía tal como hoy la entendemos (cuando lo hace, no es para sus practicantes lo que hoy es para nosotros) sino varios siglos antes: aparece con el invento de la perspectiva y, aún más, con la invención de ciertos artilugios ópticos cuyo uso, siempre amparado en un misterio del que dependía su propia supervivencia, se constituye en la herramienta secreta que numerosos artistas (y no 
solo Vermeer o Canaletto) van a emplear para dar al mundo una nueva visión de la realidad.

La captación del momento preciso e irrepetible constituye la esencia que hace de la fotografía la culminación de un deseo sentido por tantos y tantos artistas plásticos durante siglos. ¿Qué habrían hecho Velázquez o Vermeer, por ejemplo, si hubieran dispuesto de una cámara fotográfica? He dicho "fotográfica" porque una "cámara" sí que usaron, aunque sin material sensible, claro está.

Esto nos lleva a plantear unas interrogantes: ¿Existe una manera "fotográfica" de ver? ¿Existía incluso antes de aparecer la fotografía como tal, como síntesis de óptica y química? ¿Influyó la pintura a la fotografía, ha influido la fotografía a la pintura o ambas artes son hijas de una misma finalidad, de una misma forma de ver el mundo y entender la vida? ¿Y acaso la pintura no cedió el terreno del testimonio a la fotografía y ahora, mediante los procesos informáticos de manipulación de imágenes ésta vuelve a trascender el plano de la instantaneidad para ser de nuevo manipulada, como si de un cuadro se tratara?

Las respuestas las encontramos gracias, en primer lugar, al estudio comparativo de numerosas imágenes, algunas de las cuales ilustran el trabajo y apoyan el desarrollo teórico, para el cual ha sido imprescindible la consulta de diversas páginas web de museos e instituciones.

En segundo pero no menos importante, el estudio de diversas fuentes bibliográficas especializadas en un tema que despierta inevitables controversias.

\section{RESULTADOS}

\subsection{Jan Vermeer, el pintor de delft}

La vida de Vermeer y su familia no es demasiado conocida. Su padre, Reyner Janszoon Vos, había nacido en 1591, posiblemente en Amberes. Tras cumplir los 20 años marcha a Amsterdam para aprender las técnicas del tejido de la seda y se casa en 1615 con Digna Baltens. Se instalan en Delft, donde alquilan una hostería de nombre "Vos" -el zorro, en referencia a su apellido-, aunque continúan con los trabajos de tejedor. También se dedicó al comercio de objetos artísticos, por lo que ingresó en el gremio de San Lucas de la ciudad. Hacia 1625 Reyner utilizaba ya el apellido Vermeer. Jan Vermeer fue bautizado en Delft el 31 de octubre de 1632 como segundo hijo y único varón del matrimonio.

Cuando el pequeño tiene nueve años, sus padres adquieren la hostería "Mechelen", situada en una zona privilegiada de Delft, en el norte del Marktvelde, contando entre sus clientes con la burguesía distinguida de la ciudad. Entre estos clientes se encuentran también un buen número de artistas, que serán decisivos para la formación del joven pintor.

Tampoco está documentado el periodo de aprendizaje del joven Vermmeer, aunque se sabe que en diciembre de 1653 fue admitido como maetro del gemio de San Lucas de Delft. Como quiera que para ser miembro era necesario pasar seis años 
con uno de los artistas reconocidos por la "guilda", casi todos los expertos coinciden en señalar a Carel Fabritius como el maestro de Vermeer, ya que Fabritius se instaló en Delft en 1650, ingresando en el gremio de San Lucas dos años más tarde. En algunos documentos de la época se hace referencia a Jan como el sucesor de Fabritius, dato en el que se basan los especialistas para afirmar la existencia de este aprendizaje. Jan contrae matrimonio el 20 de abril de 1653 con Catharina Bolnes, hija de Maria Thins, mujer que disfrutaba de una buena posición y que en un primer momento se opuso al matrimonio, tanto por razones financieras como religiosas, ya que ella y su familia profesaban el catolicismo, mientras que los Vermeer eran calvinistas. Algunos expertos han apuntado a que Jan se convirtió al catolicismo para contraer matrimonio con Catharina, dato que no está documentado.

Los recién casados se instalaron en un primer momento en la pensión "Mechelen" pero siete años después se trasladaban a la casa de Maria Thins, sita en el barrio católico, en Oude Langendijk. Los Vermeer no tenian dificultades para alimentar a sus quince hijos, aunque cuatro de ellos fallecieran a edad temprana, lo que hace pensar que Jan no sólo vivía de los ingresos de la pintura, disciplina en laq que no fue prolífico, ya que no ejecutaba más de dos obras al año. Seguramente sus ingresos eran mayores en su otra actividad, la regencia de la hostería y en el comercio de obras de arte, siguiendo también el negocio familiar.

En 1662 es elegido síndico del gremio de San Lucas, cargo que volvió a ocupar ocho años más tarde. Maria Thins, la suegra de Vermeer, tenía también una más que aceptable posición económica al obtener importantes rentas de sus inmuebles, fincas de labranza y los créditos que concedía. Al parecer poseía una mansión de 11 habitaciones, en cuya planta inferior vivía Vermeer con su familia, utilizando la superior como estudio, con su suelo ajedrezado y la mesa de roble que aparecen en muchas de sus obras.

En 1672 viaja a La Haya, llamado por Friedrich Wilhelm, Gran Elector de Brandeburgo con el encargo de tasar unos cuadros que había comprado al famoso marchante Gerard Uylemburgh. Vermeer impugna sin reparo a varios genios del Renacimiento, declarando que la colección valdría una décima parte de lo solicitado por el marchante. La guerra que en el mismo año de 1672 estalla entre Francia y las Provincias Unidas, al penetrar Luis XIV con un ejército de 100.000 hombres en los Países Bajos, provocará la ruina de los propietarios de tierras y una crisis generalizada. La situación económica de la familia se deteriora, hasta el punto de que el pintor cae en una profunda depresión y fallece el 15 de diciembre de 1675, dejando once hijos menores de edad y a una viuda en una pésima situación financiera. En 1688 Catharina Bolnes fallecía sin poder asistir a la venta de la mayoría de los cuadros de su esposo, celebrada en una subasta en 1696, que se vendieron en precios muy elevados, como los 200 florines por la Vista de Delft o los 150 florines de la Tasadora de perlas.

\subsection{La técnica de Vermeer. Análisis}

Vermeer no fue un pintor muy prolífico. Con certeza no le son atribuidas más que 35 o 36 obras, de las cuales, la mayoría son escenas realizadas en interiores y de estas, la gran mayoría en su estudio. Hay varios indicios de que Jan Vermeer usó la cámara oscura cuando compuso la "Vista de Delf" (fig.1), "Muchacha con sombrero 
rojo" (fig.2) y otros. En estas composiciones fueron incorporados dos elementos que no eran normalmente observados por el ojo desentrenado. El efecto "Bloom" (fluorescencia) de luz alrededor del cordaje del barco en el primer cuadro y el desenfoque de la cabeza de león tallada en la silla, en el segundo, son características ópticas, no retinianas y difícilmente el artista habría pintado en esta época un "desenfoque", a menos que lo estuviese viendo.
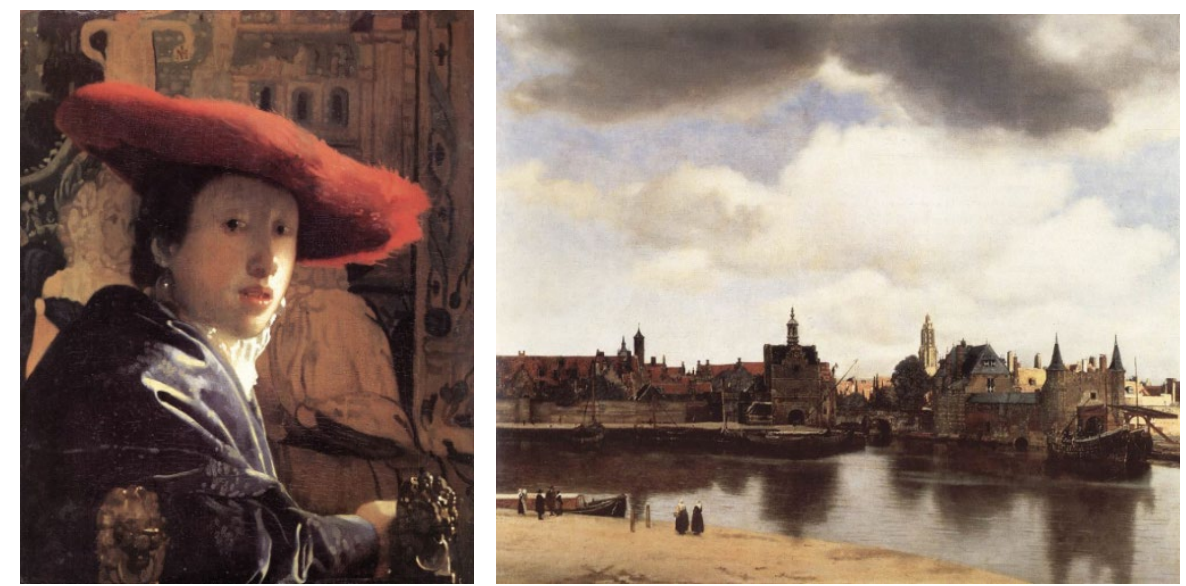

Figuras 1 y 2. Vermeer. Muchacha con sombrero rojo (1668) National Gallery of Art, Washington y Vista de Delf (1659-60) M. Mauritshuis, La Haya.

Quizá Vermeer, junto con Canaleto, es el pintor de esta época que más claramente se sirvió de la ayuda de la óptica. Su visión "fotográfica" de la realidad es hoy por hoy, un hecho reconocido y fácil de demostrar con la simple observación de algunos indicios evidentes:

\subsubsection{La visión por planos}

En Vermeer los objetos de los primeros planos adquieren gran importancia. Tomemos como ejemplo "Soldado y muchacha sonriente", en el cual el tamaño del hombre en primer término es desproporcionadamente mayor que el de la joven, un efecto que se observa al utilizar en una cámara un objetivo de corta distancia ocal cuando el sujeto está próximo a la cámara (Fig. 3).

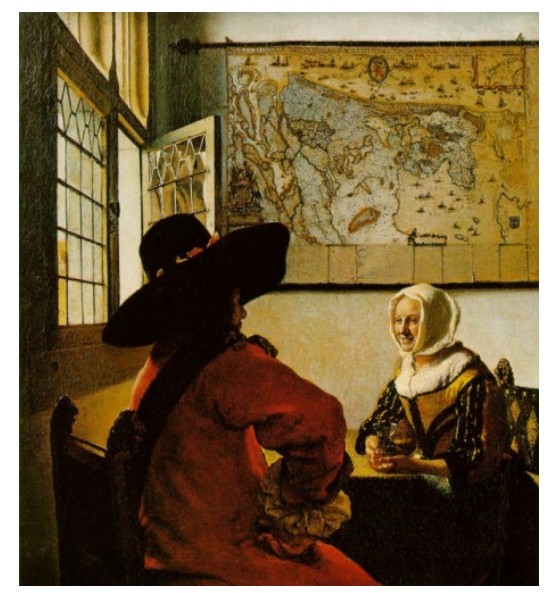

Fig. 3. Vermeer. Soldado y muchacha sonriente. (1658). The Frick Collection, New York. 


\subsubsection{El Desenfoque}

El concepto de profundidad de campo es algo cotidiano en fotografía y cine. En "La lechera" los primeros planos están ligeramente desenfocados, mientras que en la pared del fondo se ven los pequeños desconchones de los clavos. Un fotógrafo diría que "el foco está en la figura" y por lo tanto, el primer término aparece ligeramente desenfocado (Fig. 4).

Se ha dicho que Vermeer pintaba desenfocado y, en efecto, si analizamos los cuadros de algunos de sus contemporáneos, observamos la búsqueda de un realismo absoluto, un contorno preciso, una nitidez total con toda la escena perfectamente "enfocada". En cambio Vermeer se propone pintar la impresión luminosa de un instante dado y el contorno para él tiene menos importancia: visión fotográfica.
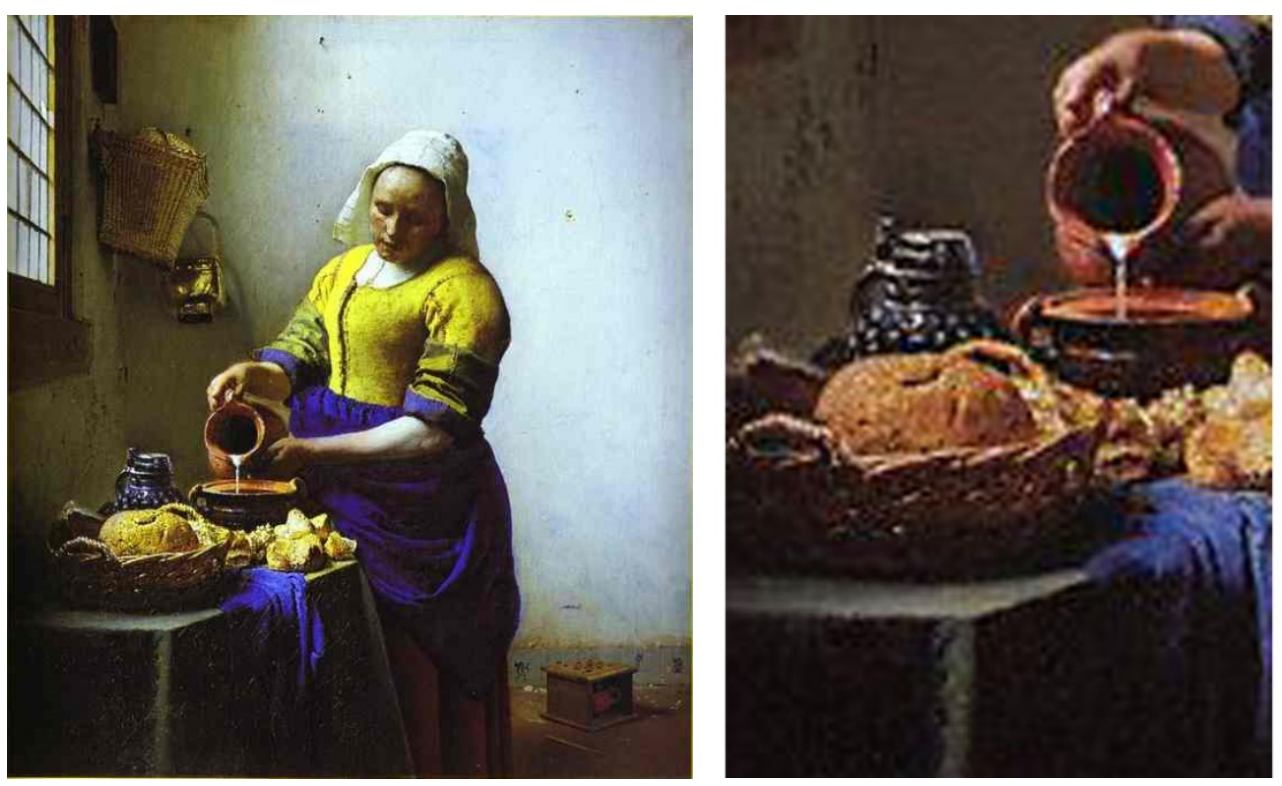

Fig. 4. Vermeer. La Lechera (y detalle, con el desenfoque) (1658). Rijksmuseum, Amsterdam.

\subsubsection{El rigor de la perspectiva}

La perspectiva central es característica de la visión proporcionada por la cámara (Fig. 4.b). A menudo, cuando la perspectiva formaba escorzos, los pintores hacían trampas. Vermeer en cambio, acepta y resuelve sin problemas los escorzos del brazo de La lechera, de las manos del pintor y del geógrafo (Figs. 6 y 7).

\subsubsection{El Puntillismo}

Si se varía el enfoque de un objetivo, al no coincidir el plano de la imagen con el de enfoque, los puntos brillantes se transforman en pequeños círculos (llamados círculos de confusión). 


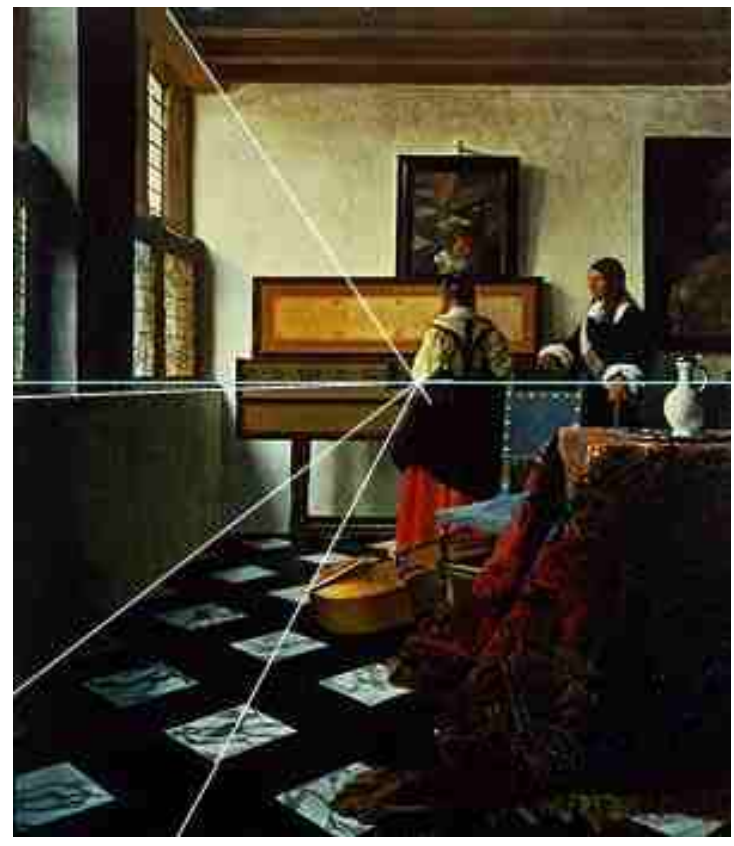

Fig. 5. Vermeer. La lección de música. 1662-1665. Colección Real. Palacio de St. James. Londres. Inglaterra. Líneas de perspectiva.

Pues bien, en algunos cuadros de Vermeer, precisamente donde los objetos están desenfocados aparecen numerosos puntos brillantes que se delatan como círculos de confusión en el plano focal de una cámara. El pintor no pudo ver ese efecto con el ojo desnudo, luego es evidente que lo hizo mirando a través de un objetivo. Como Charles Seymour (Hokney, 2001)) ha apuntado respecto a los punteados de pigmento excesivo en la "Vista de Delf" (fig. 1):

Las altas luces diseminadas en pequeños círculos en la sólida imagen de una barca están muy cerca del bien conocido fenómeno de los círculos de confusión, en términos ópticos y fotográficos. Este efecto resulta cuando un rayo de luz reflejada como un punto de un objeto de la naturaleza pasa a través de una lente y no es resuelto o "tomado a foco" sobre un plano colocado verticalmente sobre la cara de la imagen de la lente. Respecto a la pintura, este fenómeno óptico debió haberlo visto Vermeer y hay que asumir que no pudo haberlo visto con visión directa, pues es un fenómeno de luz refractada.

\subsubsection{El formato de los cuadros}

Una lente circular proyecta en el vidrio esmerilado una imagen circular o ligeramente ovalada. Un cuadrado o un rectángulo apenas pronunciado son las figuras más prácticas para aprovechar la imagen al máximo. Es fácil observar que prácticamente todos los cuadros de Vermeer tiene unas proporciones similares, rectangulares cercanas al cuadrado.

Gran número de composiciones de Vermeer pueden deber sus ángulos de vista, en extremo amplios, al fenómeno óptico asociado con la cámara oscura en un momento en que estos efectos no eran experimentados en la visión normal: empleo de lentes de distancia focal corta, que eran los utilizados debido a la poca luminosidad de los objetivos de la época. 

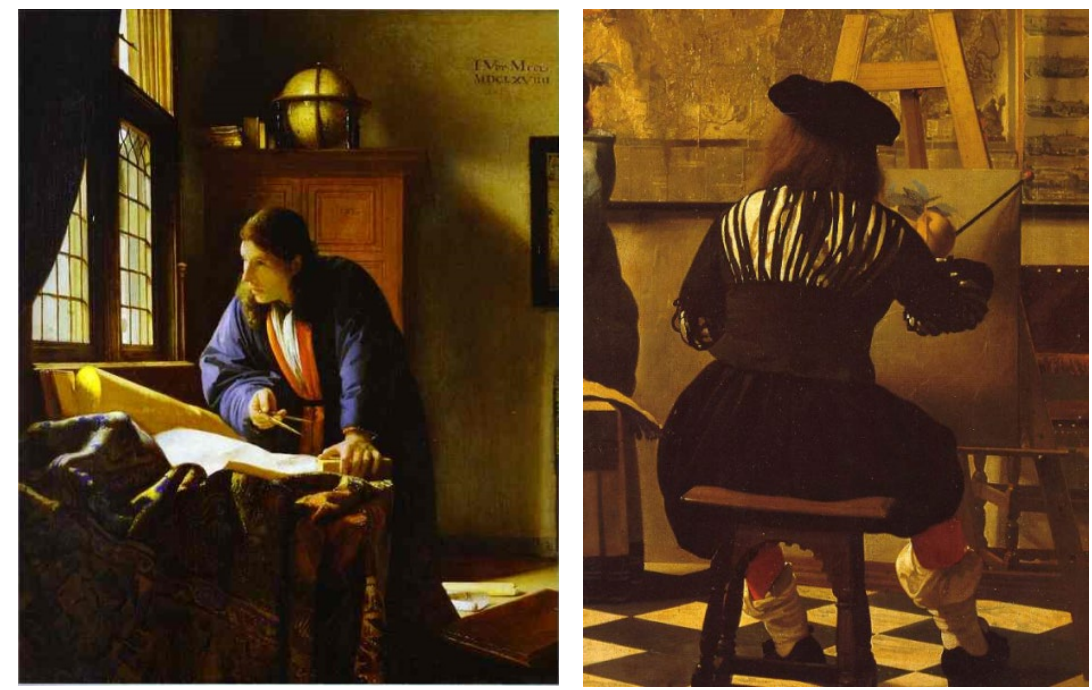

Fig. 6 y 7. Vermeer. El geógrafo (1668-1669. Stadelsches Kunstinstitut. Frankfurt. Alemania) y El Arte de la pintura (detalle) Kunsthistorisches Museum. Viena. Austria.

\subsubsection{Los excesos de luz}

Lo que un fotógrafo llamaría "zonas sobreexpuestas" son también característicos de la observación a través de la cámara. Vermeer suprime la línea saliente de la nariz de la Joven del velo o de la Joven de la Perla fundiendo la nariz con la mejilla iluminada de las modelos (Fig. 8 y 9). Curiosamente ésta es una técnica muy empleada por los modernos fotógrafos de moda.

Vermeer no dejó datos sobre su método de trabajo, pero las modernas investigaciones científicas han revelado mucho sobre esa treintena de obras que se le atribuyen. No se conoce ningún dibujo o boceto preliminar y otro detalle que no deja de ser significativo, además, es el de que recientes estudios realizados con rayos $X$ sobre algunas pinturas de Vermeer han revelado que bajo las capas de color existe una primera base de pintura en blanco y negro pero ninguna línea de dibujo preparatoria, como habría sucedido de haberse gestado la obra de forma convencional.
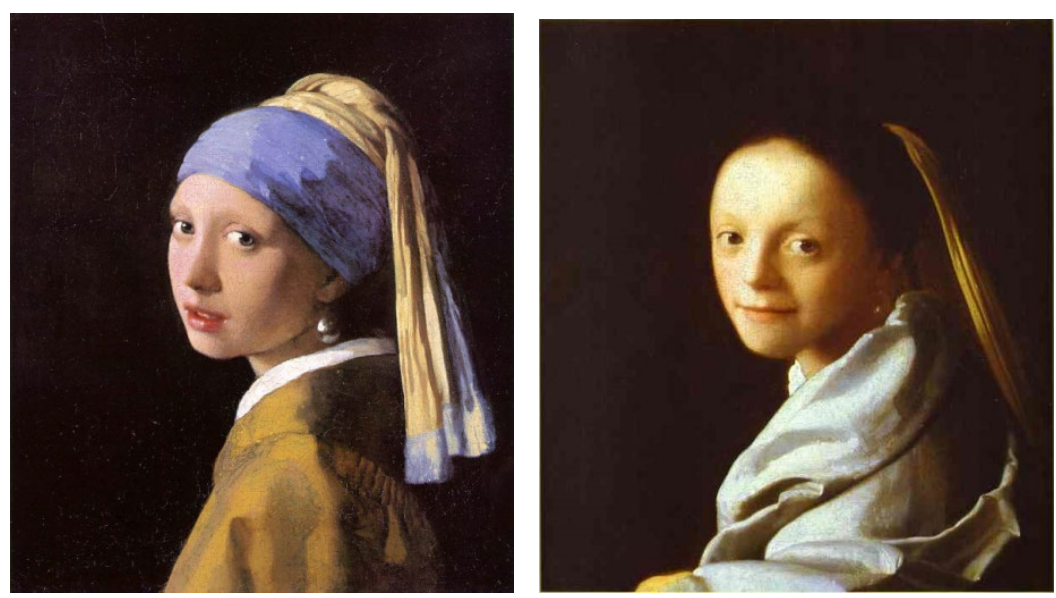

Figs. 8 y 9. Vermeer. La joven de la perla (1665, Royal Cabinet of Paintings Mauritshuis, La Haya) y Muchacha con velo (1666, Metropolitan Museum of Art, New York). 
Como ya hemos visto, la lente utilizada por Vermeer era muy poco luminosa y la imagen que obtenía no revelaba el color suficientemente, así que el pintor realizaba primero una imagen en blanco y negro para después "iluminarla" con el radiante y luminoso color que le caracterizaba.

Como apunta el profesor Philip Steadman (http://www.grand-illusions.com Visitado el 23-1-2013), la segunda mitad del siglo XVII se conoció en Holanda como su "Edad Dorada", y en ella se realizaron extraordinarios descubrimientos en la ciencia y en particular en la óptica, una floración extraordinaria en el arte y relevantes hechos de navegación y descubrimientos, ya que de una nación marinera se trataba. Así que Vermeer que nació en 1632, vivió durante una época increíblemente excitante. Pero Delft es un pueblo pequeño, aburrido, y Vermeer pasó toda su vida allí. ¿Cómo pudo aprender el uso de las lentes? ¿Y cómo pudo conseguirlas? Un contemporáneo de Vermeer (nacieron el mismo mes en Delft), Anton Leeuwenhoek, que ha pasado a la historia como microbiólogo y óptico (construyó microscopios de gran precisión) era amigo de Vermeer (se dice que fue el modelo de "El Geógrafo") y a su muerte fue su albacea testamentario. No es aventurado pensar que, como gran experto en óptica y lentes, fuera él quien instruyera a Vermeer en su utilización.

Es muy ilustrativo como Tracy Chevalier en su novella "La joven de la perla" (llevada al cine con acierto por Peter Webber), describe el asombro que produce en la ignorante sirvienta de Vermeer la contemplación de la imagen producida por las lentes.

El uso de una cámara para crear una pintura, a la manera de Vermeer, habría sido algo muy polémico en una época en la que lo que no se comprendía era tildado de "mágico" y corría el riesgo de ser "maléfico" y conducir a su autor a la hoguera. Se sabe que Vermeer no acostumbraba a llevar visitantes a su estudio y que no tuvo ningún discípulo o estudiante. Su visión fotográfica, su técnica visionaria y científica se adelantó mucho a su tiempo y no es extraño que sus obras comenzasen a ser apreciadas hace un siglo, época en que, por otra parte, las imágenes comienzan a ser producidas directamente por una cámara y aceptadas como tal.

\subsection{Canaletto. La venecia inventada a través de la cámara}

Durante la primera mitad del siglo XVIII, Venecia conoció un periodo de gran esplendor en las ciencias y las artes. Mientras crecía su fama de ciudad del lujo y los placeres, sufría una gran tensión espiritual pues en su seno, se vivía una bulliciosa actividad que, en el campo artístico, confería a la ciudad la categoría de emporio mundial y punto de difusión de miles de obras de arte de todo tipo y procedencia.

En este marco nace en 1697 Giovanni Antonio Canal, más conocido como "el Canaletto". Hijo de un pintor que trabajaba como escenógrafo, comenzó su carrera artística pintando decorados para el teatro. Un viaje a Roma en 1719 lo encaminó hacia el género de la veduta (vista), que por entonces triunfaba de la mano de artistas como Pannini y Carlevaris. De 1723 datan sus primeras vistas de Venecia, caracterizadas por intensos efectos de claroscuro que deben mucho a su anterior profesión de escenógrafo. Más tarde, su paleta se aclaró para dar vida a las obras que mejor caracterizan su creación artística, inundadas de luminosidad. 
Todos los rincones de la Venecia de la época aparecen retratados en las vistas de Canaletto, animados por la presencia de pequeñas figuras dedicadas a sus actividades cotidianas. Sin embargo el realismo de las vistas de Canaletto es sólo aparente, ya que no tiene ningún problema en alterar la realidad para embellecerla. Sus perspectivas suelen estar falseadas, los edificios aparecen engrandecidos o estilizados o cambiados de lugar. A pesar de cambiarlo todo, sus vistas de Venecia eran tan creíbles que los propios venecianos solían "picar"; alguno llegaba a decir: "tengo que ir a ver esa plaza que todavía no conozco."

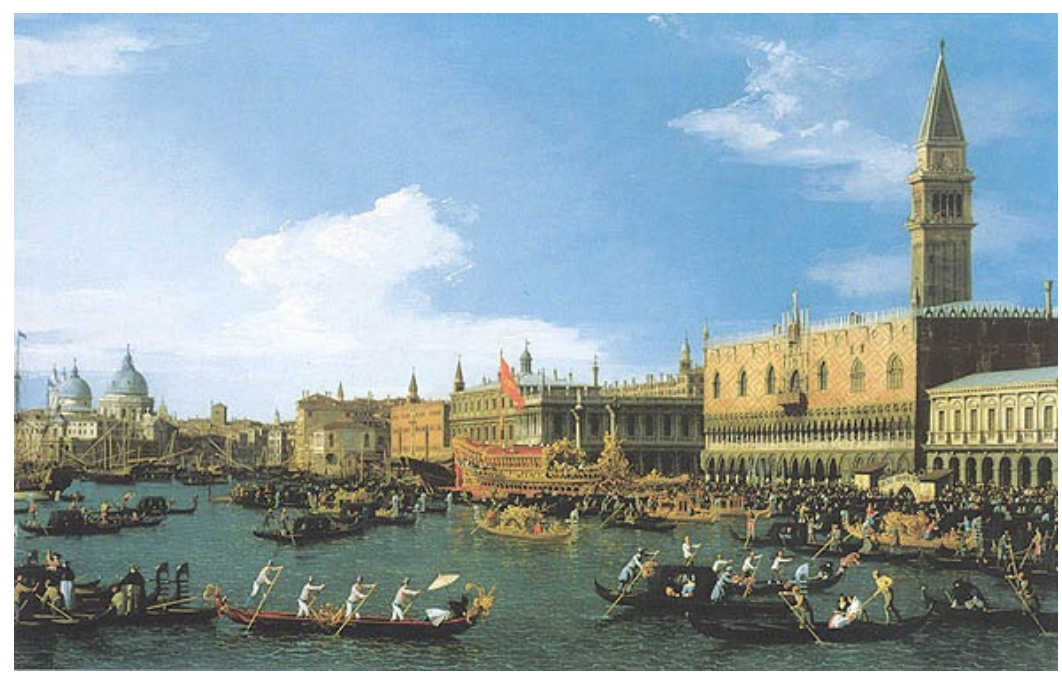

Fig. 10. Canaletto. El Bucentauro el día de la Ascensión (1745-1750). Museo Thyssen-Bornemisza. Madrid.

Y esa plaza tan "veneciana" no existía en realidad, había sido un invento de Canaletto. O: "hubiera jurado que ese pozo estaba en el centro de la plaza" cuando era así de verdad pero el pintor lo había desplazado para embellecer la vista:

Canaletto, obedeciendo a exigencias específicamente pictóricas, modifica los meandros del Gran Canal, acerca o aleja el fondo, modifica los perfiles de los tejados y simplifica las arquitecturas, abre las fachadas laterales para mostrar los escorzos más satisfactorios. $Y$ detrás de todo ello no hay un dibujo preparatorio, sino la combinación de múltiples esbozos "del natural" que al confluir en la obra definitiva la hacen tan "verdadera" que sus propios contemporáneos llegaban a pensar que el artista había pintado lo que veían sus ojos".(Succi/Delnieri, 2001).

El vedutista no imita todo lo que captan sus ojos sino que elabora equivalencias, tiende a crear un efecto realista, cosa muy distinta de la "exactitud fotográfica"...Aquel que quiera desprenderse del prejuicio realista llegará a la curiosa conclusión de que toda veduta es una excusa para la fantasía. (Succi/Delnieri, 2001).

La Venecia de la vedutta se rebela así como una ciudad construida ad hoc. Pero es un error pensar que Canaletto o Guardi plantaban su caballete en el puente de Rialto, al estilo de los impresionistas, sino que elaboraban sus imágenes en una serie de complejas operaciones realizadas en su estudio, mediante la conjugación 
de diversos apuntes del natural, a menudo realizados con la ayuda de la cámara oscura. El concepto de "fotomontaje" o "edición en capas" planea sobre esta forma de trabajo. De hecho, estas manipulaciones no fueron advertidas hasta hace poco tiempo y siempre las vistas de Canaletto han pasado por ser casi "postales" de Venecia e, incluso, han servido para realizar estudios topográficos y comparativos de la evolución de la ciudad.

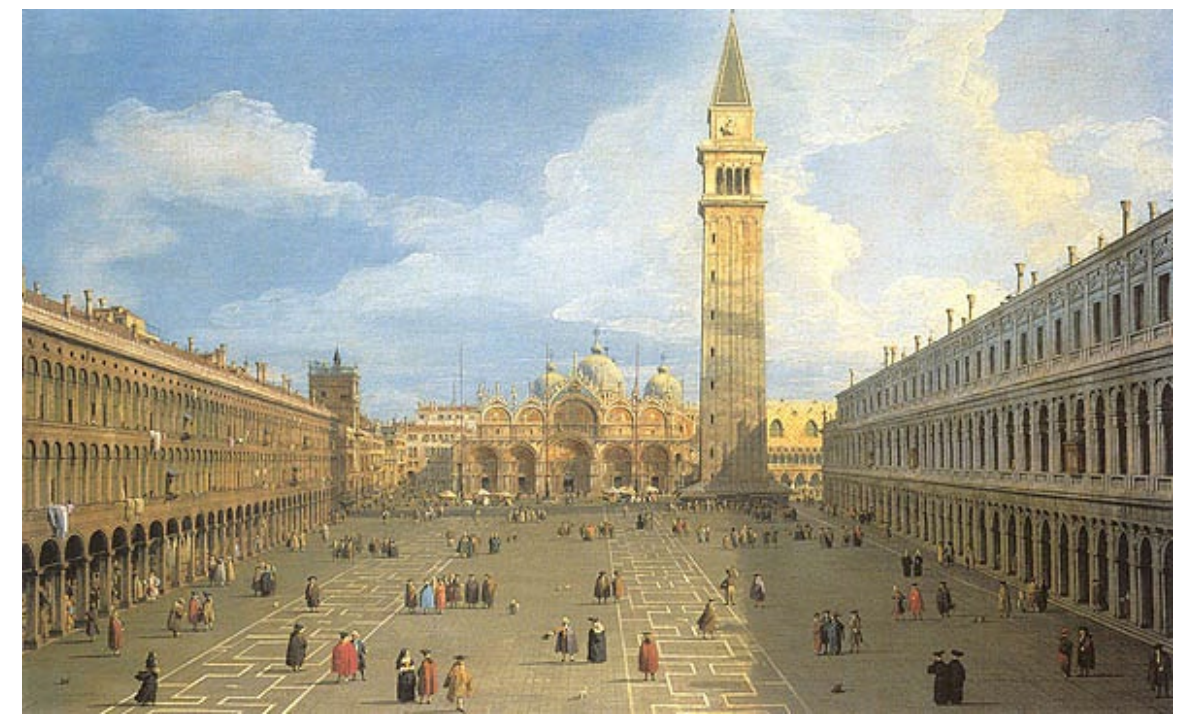

Fig. 11. Canaletto. La plaza de San Marcos hacia la Basílica.(1725).Fogg Art Museum at Harvard University. Cambridge, USA.

En el Museo Correr de Venecia, se encuentra una "caja óptica" (Fig. 4.56) con un objetivo "gran-angular" y la inscripción: "A. CANAL", que hace suponer perteneciera a Canaletto, siendo "una de las numerosas y de diversas clases de que se sirvió". (Puppi, 1981, p. 8).Sin duda a él se debe la más eficaz y segura confirmación del empleo de la cámara obscura como mecanismo auxiliar por parte de los pintores.
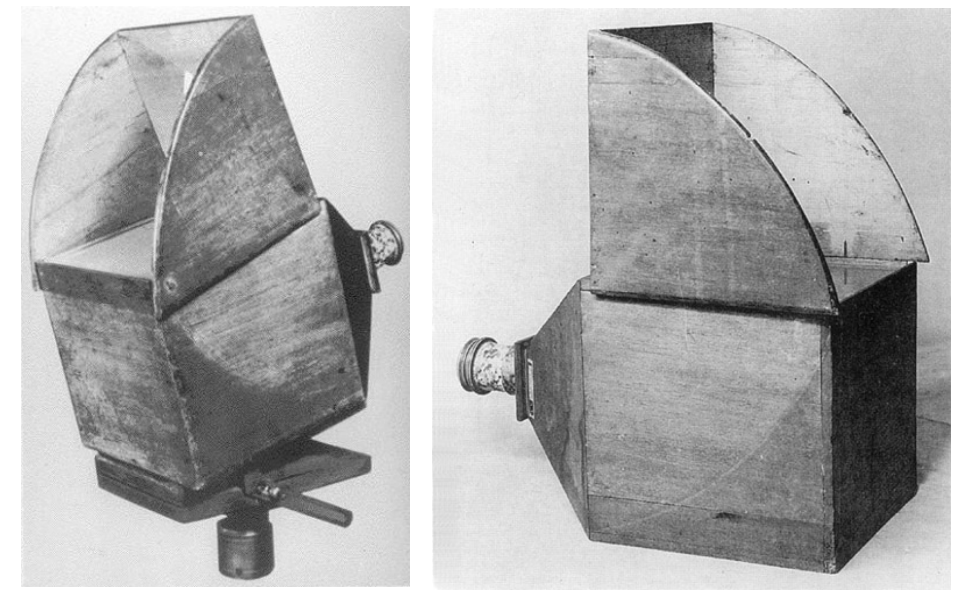

Fig. 12. Dos aspectos de la cámara óptica portátil de visor "reflex", objetivo "gran angular" y visera que se cree perteneció a Antonio Canal Canaletto.

Museo Correr de Venecia. 
Otras fuentes contemporáneas o muy poco posteriores a Canaletto confirman el uso del instrumento. El paisajista Giuseppe Zais (1709-1754) en una carta con fecha del 25 de Marzo de 1770 dirigida a un amigo que le había invitado a Bérgamo para poder "copiar vistas"; se refiere a él cuando dice: "Llevaré conmigo la caja óptica". (Puppi, 1981, p. 12).

Zanetti en Della Pittura Veneziana (Venecia, 1771), del mismo modo señala:

..... enseñó Canal el verdadero uso de la cámara óptica y a conocer los defectos que suele causar a una pintura cuando el artífice se fía completamente de la perspectiva que se ve en esa cámara y de los colores, y especialmente de las atmósferas, y no sabe quitar con destreza lo que puede molestar a los sentidos. (Wright, 1985).

Por otra parte, D. Gioseffi asegura:

Canaletto no es sólo eso: poeta no sólo de la abstracta poesía de la materia pictórica y del "gesto" gráfico como fin en si mismo, sino de inspiración suficientemente amplia para retomar como "motive" (...) el mismo dato "fotográfico", incluso donde por casualidad muestre haberse atenido "pasivamente" a éste. Por el contrario: aun cuando se quiera separar mentalmente tal aspecto fotográfico y valorarlo por separado prescindiendo (...) de la calidad de la "materia" y del carácter del signo, habrá que reconocer en suobrala presencia de casi todos los requisitos que hoy solemos exigir a la fotografía para considerarla obra de arte. Por lo que debemos creer que Antonio Canal habría sabido "hacer hablar" bien a una Leica (o filmadora), así como ha sabido hacerlo (...) con aquellas imágenes de la realidad previamente vaciadas de peso o al menos obtenidas mecánicamente. Y la elección del tema de la hora templada, el "encuadre" predispuesto, la sabiduría de la "sección", el empleo eventual de teleobjetivos y grandes angulares, el recurso nada fortuito del "fotomontaje" serían, de todos modos y por otros caminos, suficiente prenda de originalidad: indicios o testimonios de la libertad de fantasía del artista. La originalidad del fotógrafo genial, el que construye su propio discurso sirviéndose, como si fuesen palabras, de aspectos o fragmentos de la realidad visual (...) originalidad tanto mayor por cuanto habían llegado a dar sólo pocos e inseguros pasos en tal sentido. De donde resulta que le corresponde también el título de iniciador, ya que sólo con Canaletto el paradigma de la verdad fotográfica entra verdaderamente en la historia de la pintura, obligando incluso a los más reacios a tomarla en consideración. (Gioseffi, 1959, p. 36).

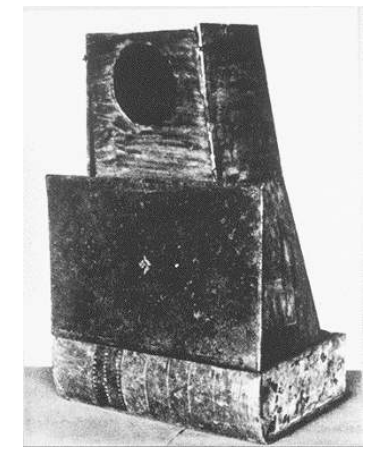

Fig. 13. Cámara plegable en forma de libro que se cree perteneció a Sir Joshua Reynolds. Museo de la Ciencia de Londres. 
L. Wright, refiriéndose a la cámara oscura, dice:

En el Museo de la Ciencia de Londres existe una cámara oscura que perteneció a Sir Joshua Reynolds: el aparato se pliega y se convierte en libro, truco tal vez pensado para hacerlo pasar inadvertido. (Fig.13).

Y refiriéndose a Canaletto, Wright asegura el uso de la cámara por parte del pintor: Igual que muchos topógrafos de su época, Canaletto recurría muchas veces a la camera óptica, y hay quien ha detectado la evidencia en algunos dibujos; aunque no podemos catalogarlos sin reservas como obras "camerográficas", ya que rara vez se consigue con la cámara la perspectiva paralela coherente, que suele ser la tónica de realización en casi todos. Cuando la cámara no está perfectamente nivelada, en los temas arquitectónicos se produce una convergencia de verticales que en un dibujo del natural el pintor elimina automáticamente. Esta convergencia impone, además, un tamaño al cuadro, quizás inadecuado para el trabajo definitivo; sin embargo, hay que admitir la posibilidad de que los pinchazos se deban al traslado de los puntos de una camerografía sobre un dibujo de mayor tamaño (o del dibujo a una pintura más grande) por medio de subdivisiones proporcionales. Quizás Canaletto destruyera las camerografías, pues a ningún artista le habría gustado que se supiera ese recurso, aunque fuera perfectamente capaz de dibujar sin él, como es el caso del propio Canaletto. (Coke, 1964, p.137).

El propio Canaletto, a este respecto reconoció:

"ll canal" enseña la forma correcta de usar la cámara y como entender los errores que ocurren en la superficie del cuadro cuando el artista sigue demasiado aproximadamente las líneas de la perspectiva, a incluso más la perspectiva aérea como aparece en la cámara (por si misma) y hace no saber cómo modificarlas en donde la precisión científica atenta contra el sentido común. (Coke, 1964, p.137).

Al decir "en donde la precisión científica atenta contra el sentido común", Canaletto se estaba refiriendo a lo que era considerado distorsión de escala en las imágenes de cámara oscura. Las cámaras oscuras estaban generalmente equipadas con lentes que creaban una imagen escorzada, en oposición con el concepto renacentista de las que eran consideradas las proporciones propias desde un punto de vista perspectivo (el "ojo único" de Brunelleschi).

Más adelante Wright apunta los datos que fueron determinantes del empleo de la cámara:

En tres dibujos a pluma de Canaletto, por ejemplo, se detectan cinco datos comunes: idéntico estilo, gran ángulo visual, anchura inhabitual en relación con la altura, anchura casi idéntica y detalle muy minucioso en relación con el tamaño. Son similitudes que sugieren el empleo de una cámara de igual lente e idéntico tamaño de papel. En un catálogo de los dibujos que se conservan en Windsor, el compendiador (que ha advertido las coincidencias y las ha agrupado) observa: La característica principal de los dibujos es la caprichosa distorsión de las distancias espaciales, mientras que las características arquitectónicas son básicamente exactas en la representación. El efecto producido es bastante parecido al que se da al observar las escenas con unos 
prismáticos al revés. Subsiste la duda de si son producto de la fantasía del pintor o en realidad las observó a través de una combinación de lentes. (Wriht, 1895).

Había a la sazón una gran demanda de este tipo de obras, sobre todo por parte de ingleses adinerados que visitaban la ciudad y, en ocasiones, encargaban al artista toda una serie de vistas de igual tamaño o sobre el mismo tema. Uno de sus principales mecenas fue el cónsul inglés Joseph Smith, para quien realizó varias series de vistas y una excepcional colección de aguafuertes. En 1746, Canaletto se trasladó a Inglaterra, donde permaneció casi diez años pintando vistas de Londres. Regresó a Venecia en el año 1755 y siguió activo hasta el fin de sus días, si bien el inventario de sus bienes efectuado a su muerte reveló que no poseía una gran fortuna, algo extraño dado el éxito de que gozó en vida y la gran cantidad de encargos que cumplimentó. Al ser su clientela preferentemente inglesa, las mejores colecciones de su obra se encuentran en los museos del Reino Unido.

\section{CONCLUSIONES}

Desde que los pintores del Quattrocento asumen la perspectiva central y comienzan a pintar tal como se ve, la tradición en las Bellas Artes siempre ha sido hostil a la producción mecánica de imágenes. Ya hemos visto cómo, desde el Renacimiento, los pintores se han cuidado muy bien de no revelar el uso de cámaras oscuras como recurso para resolver problemas de perspectiva, realizar bocetos o, simplemente, copiar.

Lo que denominamos Visión Fotográfica se basa en el carácter óptico-visual de la producción pictórica, que se concibe como algo natural, y no como producto de la sociedad. Al predominar una relación aparentemente objetiva, científica y/o natural con la realidad óptica, los pintores parecen trabajar dentro de un vacío de valores al limitarse a reproducir la realidad. El efecto acumulado de tantos siglos de representación natural/óptica es tal que, aún ahora, en pleno siglo XXI, persiste la misma actitud de comprender las imágenes realistas como algo natural: las imágenes funcionan como presentaciones y no como representaciones de la realidad.

Ambos artistas representan un modo de entender y realizar imágenes, desde esa visión fotográfica, que no puede ser entendida como un fraude sino como un adelanto de 200 años en la historia del arte.

\section{REFERENCIAS}

\section{Libros:}

Aristóteles. (1970). El Arte Poética. Madrid: Espasa Calpe.

Arnheim, R. (2002). Arte y Percepción Visual. Madrid: Alianza Forma.

Barthes, R. (1989). La Cámara Lúcida. Nota Sobre La Fotografía. Barcelona: Paidós.

Bayo Margalef, J. (1987). Percepción Y Desarrollo Cognitivo Y Artes Visuales. Barcelona: Anthropos. 
Benjamin, W. (1987). Pequeña Historia De La Fotografía. Madrid: Taurus.

Berger, J. (1998). Modos de ver. Barcelona: Gustavo Gili.

Bruce, V; Green, P. R. (1984). Percepción Visual. Barcelona: Paidós.

Brusatin, M. (1992). Historia De Las Imágenes. Madrid: Julio Ollero Editor.

Burch, N. (1995). El Tragaluz Del Infinito. Madrid: Cátedra.

Chevrier, J. F. (2007). La fotografía entre las Bellas Artes y los medios de comunicación. Barcelona: Gustavo Gili.

Coke, V. D. (1972). The Painter And The Photography. Albuquerque: University Ofnew México.

Crick, F. (1994). La búsqueda científica del alma. Madrid: Debate.

Da Vinci, Leonardo Y Alberti, L. B. (1999). El Tratado De La Pintura y los tres Libros que sobre el mismo arte escribió. Barcelona: Alta Fulla.

Da Vinci, L. (2005). Cuadernos. Edición De H. Anna Suh. New York: Parragón Books Ltd.

Damisch, H. (1997). El origen de la Perspectiva. Madrid: Alianza.

Succi, D., Delnieri, A. (2001). Canaletto y Venecia, La Ciudad Que Se Podía Construir. Catálogo de la Exposición "Canaletto, Una Venecia Imaginaria". Museo Thyssen-Bomemisza. Madrid.

Del Campo y Francés, A. (1978). La Magia de Las Meninas. Madrid: Ediciones y Publicaciones, S. A.

Denvir, B. (1993). The chronicle ofimpressionism. The Day By Day Story. London: Thames And Hudson Ltd.

Feist, P. H. (1996). El Impresionismo en Francia 1860-1920. Benedikt Taschen.

Freund. G. (1976). La Fotografía Como Documento Social. Gustavo Gili.

Frisby, L. P. (1987). Del ojo a la visión. Madrid: Alianza.

Frizot, M. (Edit.) (1998). A New History of Photography. Kónemann.

Gallego, J. (1995). Diego Velázquez. Madrid: Alianza Editorial.

Gaultier, G. (1996). Veinte lecciones sobre la imagen y el sentido. Madrid: Cátedra.

Gernsheim, H. y Gernsheim, A. (1967). Historia gráfica de la Fotografía. Omega. 
Gioseffi, D. Canaletto. (1959). II Cuaderno Delle Gallerie Veneziane El' Impiego Della Camera Ottica. Trieste.

Goethe, J. W. V. (2002). Goethe y La Ciencia. Barcelona: Siruela. Biblioteca De Ensayo.

Gombrich, E. H. (1998). Arte e ilusión. Madrid: Debate.

Gonzalez Flores, L. (2005). Fotografía y Pintura: ¿Dos medios diferentes? Barcelona: Gustavo Gili.

Hartmann, S. (1991). Critical Modernist. Ed. By Jane Calhoum Weaver.

Hockney, D. (2001). Secret Knowlodge. Londres: Thames And Hudson.

Hubert, D. (1997). El origen de la perspectiva. Madrid: Alianza Forma.

Keim, J. A. (1971). Historia De La Fotografía. Barcelona: Oikos- Tau.

Kraus, R. (2002). Lo Fotográfico. Barcelona: Gustavo Gili.

Newall, B. (1983). Historia De La Fotografía. Gustavo Gili.

Nochlin L. (1991). El Realismo. Madrid: Alianza Editorial.

Pedoe, D. (1999). La Geometría En El Arte. Barcelona: Gustavo Gili.

Pollak, P. (1997). The Picture History Ofphotography. New York: Harry N. Abrams.

Potonniée, G. (1940). Cent ans de photographie, 1839-1939. Paris: Societe D'editions Geographiques.

Puppi, L. (1981). La Obra Pictórica Completa De Canaletto. Barcelona: NoguerRizzoli.

VV. AA. (2001). Huellas de luz. El Arte y los experimentos de Henry Fox Talbot. Catálogo de la Exposición. Museo Nacional Centro De Arte Reina Sofía. Madrid.

$\underline{\text { Recursos electrónicos: }}$

Hartmann, Sadakichi

http://www.photocriticism.com/members/archiveauthors/hartmannpcca.html

Museo Correr. Venecia

http://correr.visitmuve.it/it/catalogo-opere/

Metropolitan Museum of Art, New York

http://www.metmuseum.org/collections 
Ciudad de la Pintura

http://pintura.aut.org/ 